\title{
Review of Physical Metallurgy of Creep Steel for the Design of Modern Steam Power Plants - Fundamental Theories and Parametric Models
}

\author{
V. C. Igwemezie*, C. C. Ugwuegbu, J. U. Anaele and Agu, P. C. \\ Department of Materials \& Metallurgical Engineering, Federal University of Technology, Owerri
}

Received 20 May 2015; Accepted 9 December 2015

\begin{abstract}
The need for electricity supply has increased tremendously in recent time thereby necessitating an improvement in the efficiency of steam power plant. A greater efficiency leads to a saving in fuel for a given electricity output with a consequential reduction in the rate at which damage is done to the earth's environment. This paper looks at the physical metallurgy theories and parametric models that have been the bases in the design of steel for power plant applications.
\end{abstract}

Keywords: power plant, phase transformations, creep steel, models

\section{Introduction}

In a power station heat is produced by burning coal, oil, or natural gas within a furnace [1]. This heat is converted into mechanical work energy of shaft rotation, and this mechanical energy is converted to electrical energy by a generator. Fig. 1.1 illustrates these processes using Coal fired power plant.

In steam power plant the basic operation involves pumping water from a common feed main using feed pumps. The feedwater first passes through a compartment referred to as the economizer and into the steam drum. The economizer is usually situated next to the tubes containing the exit steam from the furnace walls and so it is used to preheat the feedwater [1].

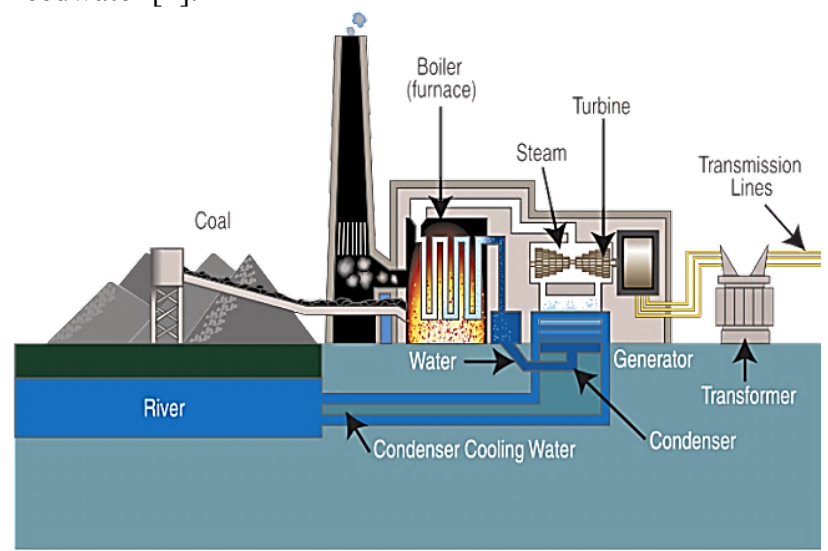

Fig. 1. Coal fired power plant diagram [www.tva.com]

$$
\text { * E-mail address: vc.igwemezie@gmail.com }
$$

ISSN: 1791-2377 (c) 2015 Kavala Institute of Technology. All rights reserved.
The water is then drawn from the steam drum into the boiler, subsequently returning to the drum as a mixture of water and steam.

The liquid water and steam can coexist when the operating pressure is below about $22 \mathrm{MPa}$. The steam is subsequently separated from water and passed on to superheaters where it is superheated close to the metallurgical temperature limit [2][3]. The superheater could be integrated with the boiler to form one unit as shown in Fig. 2 or may be a separate unit.

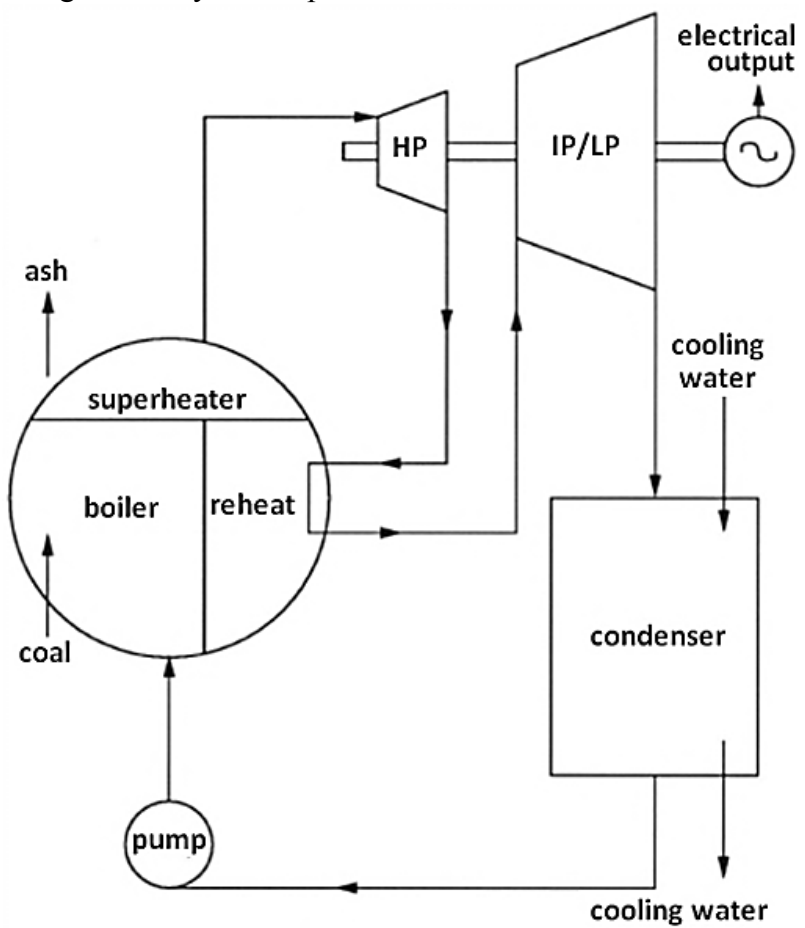

Fig. 2. Power plant operating on steam cycle with superheat and a reheat showing the route for water and steam circulation (adapted from [1]). 
The steam moves through series of pressures onto the turbine blades to rotate the turbine. Many modern turbine generators have three distinct stages or turbine set; the highpressure (HP) turbine where the superheated steam from the boiler moving under extremely high pressure is directed through nozzles onto the turbine blades. The steam spins the turbine blades or in other words does work, and in doing so reduces in temperature and pressure to an intermediate pressure (IP). The exhaust steam from the HP cylinder is then returned to the boiler to pass through a reheater where it is reheated back to a high temperature at near-constant pressure. The reheated steam is then passed into an intermediate pressure (IP) turbine. The exhaust steam that exits the IP turbine is then passed directly into the low pressure (LP) turbine where it is expanded down to the pressure appropriate for the condenser or the condenser pressure [1][3]

The various turbines are coupled to drive the rotor of the generator to produce electricity power (Fig. 1).

The turbine is designed such that the drop in pressure of the steam occurs in small fractional expansions over a large number of blades arranged in series. This condition ensures that the velocity of the steam nowhere should be great. Of course, the volume of the steam gradually increases with the successive reduction in pressure, hence the succeeding turbines are designed to be larger in terms of the blade height and diameter [2].

We have gas turbine power stations, gas-fired steam power stations and coal-fired steam power stations. State-ofthe-art plants attempts to combine these principles, i.e. modern power station has both the gas and steam turbines and is known as combined-cycle gas turbine power plants (CCGT). The greatest variation in the design of these plants is due to the type of fuel it is meant to use. The basic principle of power plant is the same for all power plants (Fig. 1).

The thermal efficiency of power plant describes how well it converts heat to work, for example by burning coal, which is converted into electricity. The Carnot efficiency, $\eta_{C}$ based on an ideal cycle is given as

$\eta_{C}=\frac{T_{\text {inlet }}-T_{\text {exhaust }}}{T_{\text {inlet }}} \times 100 \%$

where $T_{\text {inlet }}$ is the absolute temperature at the engine inlet and $T_{\text {exhaust }}$ is the absolute temperature at the exhaust, which not below $27^{\circ} \mathrm{C}$. The temperature $T_{\text {inlet }}$ is what is referred to as the metallurgical limit.

The need for electricity supply has increased tremendously in recent time thereby necessitating an improvement in the efficiency of steam power plant. The increased concern over rising fuel costs and availability coupled with the drive to reduce emissions of gases such as $\mathrm{CO}_{2}, \mathrm{NO}_{x}$ and $\mathrm{SO}_{x}$ has further emphasized the importance of increasing plant efficiency[4]. A greater efficiency leads to a saving in fuel for a given electricity output with a consequential reduction in the rate at which damage is done to the earth's environment [2]. Hence, Energy security combined with lower carbon emission is increasingly quoted to protect global environment in the 21 st century.

Equation 1 simply shows that the wider the difference between $T_{\text {inlet }}$ and $T_{\text {exhaust }}$, the more efficient is the thermodynamic cycle. To maximize efficiency the steam turbine has to be operated near the limit, usually achieved by superheating the steam [3]. In general, the efficiency of steam turbines can be improved by increasing the maximum operating pressure and temperature [2].

In practice, the inlet temperature (maximum temperature), which determines the efficiency of the power plant is limited by the availability of creep steel that is commonly used to construct those parts that are subjected to high stresses and oxidation in the plant.

Table 1 shows typical operating parameters for steels used in the manufacture of power plant.

Table 1. Service condition of the hottest part of a power plant [Lower bound conditions are representative of common technology]. The stress is a 100000 hour creep rupture strength [5][6] [7].

\begin{tabular}{c|c} 
Temperature & $540-570{ }^{\circ} \mathrm{C}$ \\
Pressure & $50-370 \mathrm{bar}$ \\
Design Life & $2,5 \times 10^{5} \mathrm{~h}$ \\
$\boldsymbol{\Sigma}_{\mathbf{1 0 0 0 0 h}}$ & $100 \mathrm{Mpa}$ \\
\hline
\end{tabular}

It should be noted that the bounds are not rigid.

The most significant increases in steam turbine efficiency may be obtained by raising the steam temperature. An increase in steam condition from $538^{\circ} \mathrm{C}$ at a pressure of $30 \mathrm{Mpa}$ to $650{ }^{\circ} \mathrm{C}$ at $40 \mathrm{Mpa}$ is expected to raise turbine efficiency by $8 \%$ [3][8].

Abe (1999) in his publication reported that increase in steam parameters from the conventional $536 / 566^{\circ} \mathrm{C}$ and 24.1 Mpa to $650 / 593^{\circ} \mathrm{C}$ and $34.3 \mathrm{Mpa}$ causes an increase in relative efficiency of $6.5 \%$, which results in significant coal (energy) saving and hence the reduction of $\mathrm{CO}_{2}$ emissions [9][10].

It has been reported [2] that there are now more than 400 power plant in the world which operate on somewhat modified conditions than those given in Table 1.1. One of the modifications is raising the pressure to a value greater than $22 \mathrm{MPa}$. The increase in pressure now causes the water to exist entirely in the gaseous state. In other words, in these plants there is no distinction between the liquid and gaseous states of water. The use of high pressure here increases the efficiency of the plant to about $45 \%$ and if the steam temperature is also increased (ultra-supercritical conditions) then efficiencies of $50 \%$ are possible [2].

Tancret, F. et al, (2003) stated that future fossil fuel power plants are being conceived to operate with steam temperatures as high as $750^{\circ} \mathrm{C}$. At this temperature, it is expected that the efficiency of power plant will increase from $42 \%$ with the current typical temperature of $600^{\circ} \mathrm{C}$, to $60 \%$, providing enormous savings in fuel as well as a significant reduction of polluting emissions [11].

However, to increase the efficiency of steam turbine power plant steels, degradation mechanism such as oxidation and thermal fatigue must be considered. The degree of reliability demanded of heat resistant steels is seen to be extraordinary and represents one of the highest achievements of technology.

\section{The Theory of creep in Steel}

Steel for power plant are often placed in service at elevated temperatures and exposed to static mechanical stresses (e.g., turbine rotors in steam generators that experience centrifugal stresses, and high-pressure steam lines) [12]. The steam turbine casing attains the running steam temperature during steady operation and the steam pressure is contained within 
the casing. This gives rise to a steady state stress which at elevated temperatures can cause the casing to fail [3][12].

The main components which are identified as critical in power plants are steam headers, superheater and reheater tubing in boilers, turbine valve chests, rotors and casings, main steam and reheat pipework, generator rotors and bolts used for high temperature applications [1]. Table 2 shows power plant components and typical life limiting factors.

Table 2. Typical life limiting factors for power station components. Adapted from [1]

\begin{tabular}{|l|l|}
\hline Component & Typical life limiting factor \\
\hline [1] Boilers & creep, thermal fatigue \\
\hline $\begin{array}{l}\text { Headers - superheater, } \\
\text { reheater }\end{array}$ & creep, fireside corrosion \\
\hline Superheater, reheater & fireside corrosion \\
\hline Tubes - furnace wall & weld cracking, creep \\
\hline [2] Pipework & $\begin{array}{l}\text { weld cracking, creep, bolt } \\
\text { failures, thermal fatigue }\end{array}$ \\
\hline HP and RH pipework & $\begin{array}{l}\text { Bhermal fatigue, creep, bolt } \\
\text { failures }\end{array}$ \\
\hline Boiler and turbine valves & [3] Turbines and generators \\
\hline Turbine valve chests & creep, fatigue \\
\hline Turbine HP and IP casing & creep \\
\hline Turbine HP and IP rotors & $\begin{array}{l}\text { creep, stress erosion, thermal } \\
\text { fatigue }\end{array}$ \\
\hline High temperature bolting & fatigue \\
\hline Generator rotors & \\
\hline
\end{tabular}

It is found that if steel is subjected to a constant tensile stress or load at an elevated temperature it will undergo progressive plastic deformation over a period of time [11]. The yield stress here is usually below the ordinary yield stress as measured in a tensile test. The tensile test is generally conducted under conditions where the measured properties are independent of time [13]. This phenomenon is termed creep.

The limiting factor in the use of material at elevated temperature is generally its creep strength and resistance to degradation. These factors are related to the microstructural stability of the alloy. Knowledge of the creep behaviour or prediction of creep deformation (i.e. the strain and rupture life) of metal is very important as it enables design of more reliable parts and components.

Engineering components, especially large ones, always contain defects. The important point is not the existence of these defects but that they must not be large enough to propagate rapidly and hence cause catastrophic failure. Hence, creep steel is designed to have a certain fracture toughness which defines its ability to tolerate defects. Any defect present when the component enters service can grow slowly and eventually reach a critical size where it propagates disastrously.

It is found that the most frequent cause of slow crack growth is exposure to cyclic stresses but in power plant the problem can be worsened by the combined fluctuations of stress and temperature. The two different frequencies of loading usually considered in power plant are low cycle fatigue which occurs due to discontinuous operation and high cycle fatigue caused by the cyclic motion of components [2].

In steam power plant, creep is normally an undesirable phenomenon and is the limiting factor in the lifetime of the steel part used in constructing it. Accordingly, we can say that the increase in power plant efficiency has direct relationship to availability of material that makes it possible. Therefore, the highly stressed parts and safety critical components in power plant are made of steels developed to resist deformation at high temperatures and associated pressures [14]. Many of these components are expected to serve reliably for a period of about 30 years.

It should be noted that what is high temperature for one material may not be so high for another. To compensate for this, temperature is often expressed as a homologous temperature. Homologous temperature equals the ratio of the service (test) temperature to the melting temperature of the material on an absolute temperature scale. That is,

Homologous temperature, $\left.T=\frac{T_{t}}{T_{m}}\right\}$ abs $=0.4$

Therefore, we can say that the onset of creep depends on the homologous temperature $T / T_{m}$. Generally, creep for metals becomes important only for temperatures greater than about $0.4 T_{m}$. The higher the melting temperature the higher the creep resistance of the metal since the rate of selfdiffusion is lower in metals with high $T_{m}$.

The tensile properties of most engineering metals at room temperature are independent of time for practical purposes. However, at elevated temperature the strength becomes very dependent on both strain rate and time of exposure [12][13].

Typical creep curve of strain versus time at constant stress and constant elevated temperature is shown in Fig. 3

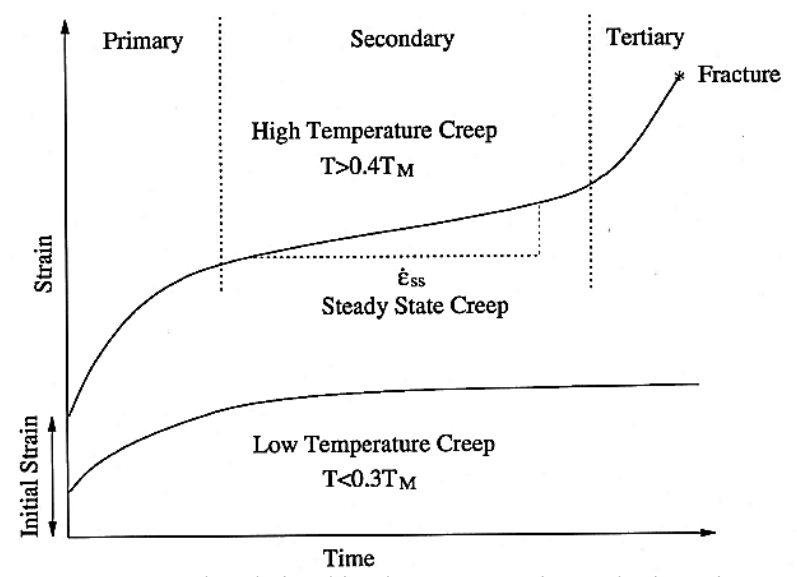

Fig. 3: General relationship between strain and time in creep deformation.

Fig. 3 shows general creep behavior of metals at low and high temperatures as a function of melting temperature $T_{m}$ of the material. Upon application of load there is an instantaneous deformation (time-independent strain), $\varepsilon_{o}$ as indicated, which is mostly elastic.

With time the strain increases further, with the creep (strain) rate changing strongly, usually decreasing continuously, i.e. the slope of the curve diminishes with time. It is a period of predominantly transient creep in which the creep resistance of the material increases by virtue of its own deformation. In other words, the material is experiencing an increase in creep resistance or strain hardening. That is, deformation becomes more difficult as the material is strained. This region of the creep curve is commonly called primary creep or transient creep. 
Beyond the primary regime, the material enters a regime where the rate is approximately constant; that is, the plot becomes linear. In other words, a steady state region is established and in the case of steel this is often the stage of creep deformation process that is of the longest duration. This is a region usually referred to as steady-state creep or secondary creep.

The constancy of creep rate in secondary creep is commonly explained on the basis of a balance between the competing processes of strain hardening and recovery, recovery being the process whereby a material becomes softer and retains its ability to experience further deformation [12].

As in time-independent plastic deformation, dislocations play an important role in the deformation of metals. At the onset of creep deformation, the number of dislocations in the material usually increases causing hardening that results in the reduction of creep rate at constant stress.

Creep is a thermally activated process and the rate of deformation is temperature sensitive. Therefore, the dislocation density generated during deformation cannot increase arbitrarily since recovery occurs simultaneously, with dislocations annihilating by climb. This process becomes the easier, the closer the dislocations are. Accordingly, after some transition time, equilibrium between the generation of additional dislocation segments by plasticity and the annihilation of dislocations by recovery will be found. This equilibrium causes the creep rate to become constant in the secondary stage.

It has been observed that this shape of the creep curve occurs only in materials that do not change their microstructure during the creep process. This is the case in simple alloys, but not in many technical alloys.

A constant strain rate is also only observed if the stress in the component is kept constant. Since the cross section of the component decreases under tensile load during the deformation, the force on the component has to be reduced over time. In service, this is usually not the case so that no region of constant strain rate is observed. In these cases, the minimum creep rate is used instead of the constant creep rate during secondary creep to quantify the creep behaviour.

The average value of the creep rate during the secondary creep is called the minimum creep rate, $\varepsilon_{s s}^{.}$. The minimum creep rate $\varepsilon_{s S}^{\cdot}$ is the slope of the linear segment in the secondary region expressed as [14]:

$\varepsilon_{S S}^{\cdot}=\frac{\Delta \varepsilon}{\Delta t}$

It has long been established that metals deform by the movement of dislocations. At high temperature, there is greater mobility of dislocations by the mechanism of climb and the equilibrium concentration of vacancies likewise increases with temperature. In some metals the slip system changes or additional slip systems are introduced with increasing temperature. Deformation at grain boundaries becomes an added possibility in the high-temperature deformation of metals. Hence, successful use of metals at high temperatures involves a number of challenging problems. The summary of the engineering requirements for application of an alloy at elevated temperature are commonly stated as follows [3].

1. High creep strength at high temperature

2. High toughness and resistance to embrittlement

3. Resistance to steam oxidation and corrosion

4. Ease of fabrication and weldability
Dislocation movement is usually impeded by particles, grain boundaries and other dislocations. At low temperature, if dislocation encounters an obstacle e.g., a precipitate, it needs a certain minimal stress to overcome or climb over the obstacle otherwise it will be stopped. In dislocation creep the dislocations overcome barriers by thermal assistance involving the diffusion of vacancies or interstitials, occurring for $10^{-4}<\frac{\sigma}{G}<10^{-2}$ [15]. In other words, at elevated temperatures, the dislocation can evade the obstacle by adding or emitting vacancies in a process referred to as dislocation climb. The atomic diffusion help to unlock dislocation from precipitates or obstacles in their path and the subsequent movement of these dislocations under the applied stress leads to dislocation creep.

At lower homologous temperatures such as $0.3-0.5 T_{M}$, core diffusion (boundary/dislocation) tends to be the dominant mechanism where atoms move through the grain itself but at higher temperatures bulk diffusion (vacancy/interstitial diffusion) becomes dominant. Depending on the temperature and the stress or external conditions, different microscopic processes are important in determining creep behaviour or mechanisms. The rate of creep is generally dependent on diffusion, stress, temperature, and grain size.

The finally stage of creep is an acceleration of the creep rate and ultimate failure. This regime is usually referred to as the tertiary creep and the failure frequently termed rupture. The tertiary creep is often associated with microstructural and/or metallurgical changes such as coarsening of precipitate particles, recrystallization, or diffusional changes in the phases that are present. These lead to grain boundary separation, formation and accumulation of internal cracks, cavities, and voids on grain surfaces [12][15]. Also, for tensile loads, a neck may form at some point within the deformation region.

These defects first become significantly visible at the start of the tertiary creep stage, and as they grow, the material effective cross-sectional area decreases. Consequently the load-bearing capacity for the material strongly reduces. The reduced cross-section causes an increase in the stress experienced by the material and since the creep rate is proportional to a power of the stress the damage leads to the tertiary creep stage and thus explains the strong increase in strain rate in the tertiary region. The degree to which these three stages are readily distinguishable depends strongly on the applied stress and temperature.

The general behaviour of the effects of both temperature and the level of the applied stress on creep characteristics are shown in Fig. 4.

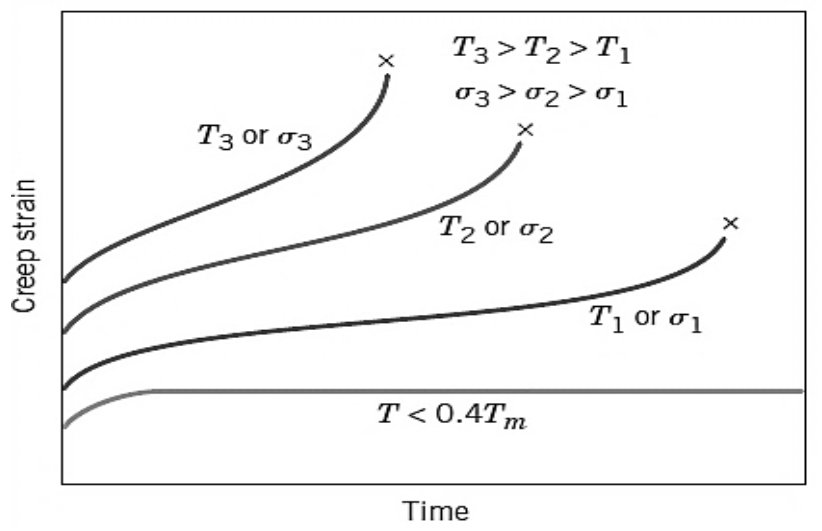

Fig. 4. Influence of stress $\sigma$ at constant temperature $T$ on creep behaviour [12][14]. 
At a temperature less than $0.4 T_{m}$ and after the initial deformation upon application of the stress, the strain is virtually independent of time. It has been observed that as the str

ess or temperature increases, the following will be noted:

1. the instantaneous strain at the time of stress application increases,

2. the steady-state creep rate is increased, and

3. the rupture lifetime is diminished.

The strain due to creep are usually very small, rarely leading to failure at low temperatures. But at elevated temperature, creep mechanism is accelerated leading to significant dimensional changes that can cause failure. At this high temperature, the initial strain, the extent of primary creep and existence of a steady-state region are found to depend on material and microstructure.

For power plant steels the creep curve could be more complex because microstructural changes occur throughout the working life. These changes include the precipitation of secondary phases which enhance creep resistance or depletion of solute in the matrix by the precipitation of coarse phases, which could be detrimental to creep resistance. Creep strength of power plant steels therefore is affected by the composition of the steel and the heat treatments applied to them. These variables control the microstructure of the alloy, including precipitation of carbides.

Studies have shown that the number of variables involved in the design of creep-resistant steels is very large in fact, Bhadeshia and co-workers identified not less than thirty variables which need to be controlled in any experiment or calculation of creep properties [6]. These variables are seen as the key components of any design as they determine the microstructure and mechanical properties of creep steel.

\section{Measurement of the Creep Resistance}

The creep resistance of a material as measured by fracture is commonly called the rupture strength. In a way of definition, rupture strength is the stress needed to cause fracture in a given time at a given temperature. Therefore, a typical creep test consists of subjecting a bar specimen to a constant load or stress while maintaining the temperature constant over a period of time; deformation or plastic strain is measured and plotted as a function of elapsed time. The elongation at fracture is usually called the rupture ductility. In a situation where a large dimensional change in the material is not really important, rupture stress is commonly used for design calculations.

Possibly, the most important parameter from a creep test is the slope of the secondary portion of the creep curve $\left(\Delta \varepsilon_{S S} / \Delta t\right)$; this is often called the minimum or steady-state creep rate $\dot{\varepsilon}_{S}$ as previously mentioned. It is the engineering design parameter that is considered for long-life applications in steam power plant component that is scheduled to operate for several decades, and when failure or too much strain are not options.

On the other hand, for many relatively short-life creep situations (e.g., turbine blades in military aircraft and rocket motor nozzles), time to rupture, or the rupture lifetime, is the dominant design consideration. The creep rupture life is frequently a fundamental limit on the design of steam turbines for power plant [3][13].

Basically, Creep-Rupture Test is similar to creep test except that the test is always carried out to the failure of the material, hence termed creep rupture test. Rupture lifetime $t_{r}$ is the total time to rupture. High loads are used with the stress rupture test than in a creep test, and therefore the creep rates are higher. Ordinarily the creep test is carried out at relatively low stresses so as to avoid tertiary creep.

In the creep test the total strain is often less than $0.5 \%$, while in the stress-rupture test the total strain may be around $50 \%$. The higher stresses and creep rates of the creep-rupture test cause structural changes to occur in metals at shorter times than would be observed ordinarily in the creep test, and therefore the test can usually be terminated in $1000 \mathrm{~h}$.

Creep-rupture test is particularly well suited to determining the relative high-temperature strength of new alloys for jet-engine applications. It has direct application in design where creep deformation can be tolerated but fracture must be prevented. Thus, a knowledge of these creep characteristics of a material allows the design engineer to ascertain its suitability for a specific application.

Basic information obtained from stress-rupture test is the time to cause failure at a given nominal stress for a constant temperature. Elongation and reduction of area at fracture are also determined. The results of creep rupture tests are most commonly presented as the logarithm of stress, $\sigma$ versus the logarithm of rupture lifetime, $t_{r}$. Fig. 5 shows typical creep diagram that plot the stress until fracture or until a certain plastic deformation is reached versus the time at a certain temperature.

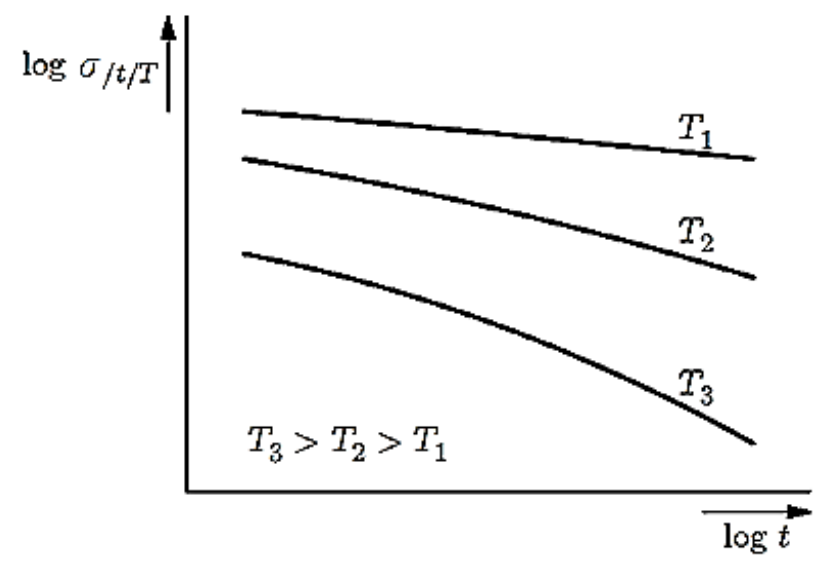

Fig. 5. Schematic creep diagram of stress vs. time [15].

At different temperatures, the stress that causes fracture after a certain time is plotted. Each point on the curve corresponds to one experiment. $\sigma / t / T$ is the stress in a specimen that fails after a time $t$ at temperature $T$. For example $\sigma / 100000 / 550$ is the failure stress after $10^{5} \mathrm{~h}$ at $550^{\circ} \mathrm{C}$. The diagram again shows that the life time at high temperatures is in principle limited because the creep strain accumulates over time.

Many power plant components have to support loads at elevated temperatures; this causes thermally activated, slow and continuous plastic strain which increases with time. For well-designed materials, this creep strain is expected to be tolerable over the design life of the component. This implies that the creep will not cause rupture or undesirable dimensional changes throughout the lifespan of the plant. A typical tolerable creep strain rate is reported to be about 
$3 \times 10^{-11} S^{-1}$, or approximately $2 \%$ elongation over 30 years or entire life of the plant [13][16].

It is also common to specify the stress (design stress) the steel will support during service or intended life of the plant without fracture. Other damage mechanisms which must also be considered include fatigue, thermal fatigue, creepfatigue, corrosion/oxidation, progressive embrittlement and, where relevant, deterioration caused by hydrogen [16]. When fracture does eventually occur, it must be associated with a certain amount of creep ductility. In the case of bolting, the relaxation of the bolting stress by creep determines the sealing life.

Empirical relationships have been developed in which the steady-state creep rate $\left(\dot{\varepsilon}_{S S}\right)$ as a function of stress $\sigma$ and temperature is expressed. Its dependence on stress $\sigma$ can be written as [12][17]:

$\dot{\varepsilon_{S S}}=K_{1} \sigma^{n}$

where $K_{1}$ and $n$ are material constants: $n$ is the creep exponent between 1 and 8 .

At high stresses a mechanism described as power-law creep occurs and $n$ is of a value between 3 and 8 . At low stresses linear-viscous creep can occur and $n \approx 1$. Here, a plot of the logarithm of $\varepsilon_{s S}^{\cdot}$ versus the logarithm of $\sigma$ yields a straight line with $n$ as the slope.

Experimentally, Ashby \& Jones (1989) observed that the temperature dependence of the steady-state creep rate is given by

$$
\dot{\varepsilon}_{S S}=K_{2} \exp \left(-\frac{Q_{c}}{\bar{R} T}\right)
$$

Where $\bar{R}$ is the Universal Gas Constant (8.31 $\left.\mathrm{Jmol}^{-1} \mathrm{~K}^{-1}\right), T$ is the absolute temperature, $K_{2}$ is a constant and $Q_{c}$ is the activation energy for creep with units of $\mathrm{Jmol}^{-1}$.

Combining Equations 3 and 4, the steady state creep rate, in theory, at low stress becomes [12][16]:

$\dot{\varepsilon}_{S S}=K_{3} \sigma^{n} \exp \left(-\frac{Q_{c}}{\bar{R} T}\right)$

where $K_{3}$ is the creep constant (empirical constant), $\sigma$ applied stress, $T$ abs temperature, $\bar{R}$ universal gas constant.

Equation 5 is called power-law creep or Norton creep and it shows that creep is a thermally activated process. The strain rate $\dot{\varepsilon}_{s s}$ depends with a power law on the stress $\sigma$ and exponentially on the temperature $T$. Note that the unit of $K_{3}$ depends on the exponent and is $s^{-1} M P a^{-n}$. To avoid this awkward unit, the stress can be normalised, for example by dividing it by Young's modulus, resulting in a unit of $s^{-1}$.

Weertman (1995) expressed equation 5 as

$\dot{\varepsilon}_{S S}=K_{3} \sigma^{n} \exp \left(-\frac{Q_{c}}{\kappa T}\right)$

Where $\kappa$ is the Boltzmann's constant.

\section{Deformation mechanism maps}

Theoretical mechanisms proposed to explain the creep behaviour for various materials are basically dislocation creep and diffusion creep.

The mechanical forces provide the driving force for diffusion which is the rate controlling process for climb to occur [14]. Diffusion is reliant on temperature and only occurs at a perceptible rate in normal materials if the temperature exceeds $0.3 T_{M}$.

Core diffusion and boundary diffusion are sometimes described as short-circuiting bulk diffusion, providing routes with low energy barriers for atoms to move along.

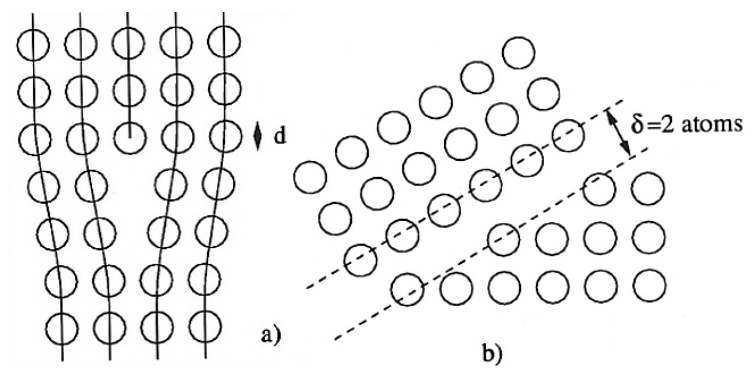

Fig. 6. schematic of a) dislocation core path for diffusion b) boundary diffusion [3]

In boundary diffusion, grain boundaries act as channels, about 2 atoms wide, creating a fast route with a low energy barrier. Fig. 6b) shows that incoherent packing creates larger gaps for atoms to fit through.

Bulk diffusion occurs through the bulk of the crystal. Two notable ways this happens are by interstitial diffusion and vacancy diffusion. Interstitial diffusion occurs by the movement of small atoms through the interstices of the crystal lattice, which are the small gaps between atoms. Small atoms such as carbon can do this, as well as such elements as $\mathrm{O}, \mathrm{N}, \mathrm{B}$, and $\mathrm{H}$ [19]. This mechanism is shown in Fig. 7.

Vacancy diffusion occurs with atoms which are too large to fit into the interstices, such as an iron atom or atoms of other elements such as W and Mo. The atom can only move when a vacancy is available for it to fill, as shown in Fig. 7 (b). Details of these mechanisms are readily available in many good literatures like [20][21]. An atom can move to site of a vacancy provided that it has sufficient thermal energy. Vacancy movement is the dominant mechanism in most metals and alloys.
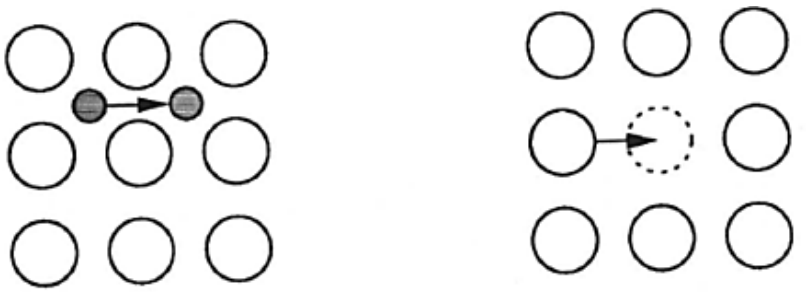

a)

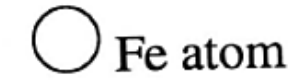

b)
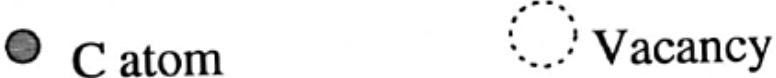

Fig. 7. schematic of a) Interstitial diffusion b) Vacancy diffusion [3]

Because the activation energy is large for bulk diffusion compared with core or boundary diffusion, it only starts at higher temperatures. However, the volume over which bulk diffusion can occur is larger, therefore more atoms can diffuse per second and so the mechanism dominates at higher temperatures.

At elevated temperatures, dislocation creep is not the only mechanism contributing to deformation. Flow of 
vacancies (or vacancy diffusion) and interstitials through a crystal can cause a deformation without any dislocations being involved. This process is called diffusion creep. As the stress is reduced the power-law creep mechanism is replaced by diffusion creep, where the applied stress is relieved by grain elongation, caused by diffusion of atoms from one side of the grain to the other (Fig. 8). In creep diffusion, grain boundaries are identified as the sources and sinks of vacancies.

In general, at high temperatures the main mechanism is bulk diffusion, where atoms move through the grain itself. At lower temperatures, where bulk diffusion becomes slow, grain boundary diffusion becomes dominant. As before, the rate of creep is dependent on diffusion, stress and temperature but now it is also controlled by grain size.

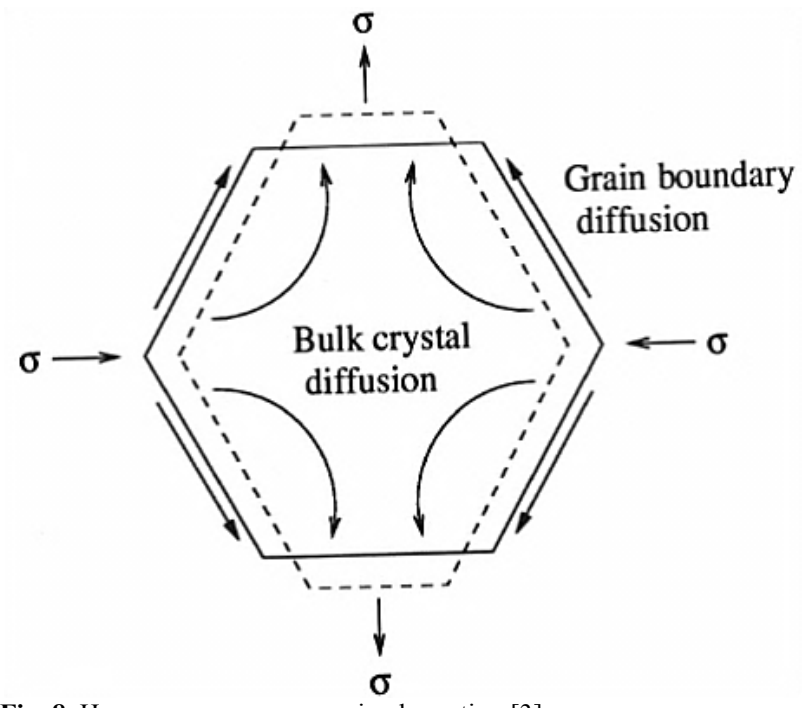

Fig. 8. How creep can cause grain elongation [3]

At high temperatures, grains in metals can move against each other. This may be as a result of formation of holes during creep and to prevent the formation of these holes between the grains, grain boundary sliding is required. This process involving the sliding of grains past each other is commonly referred to as grain boundary sliding (Fig. 9). In metals, this process contributes only slightly to the overall deformation but it is nevertheless thought to be important in ensuring grain compatibility during the deformation.

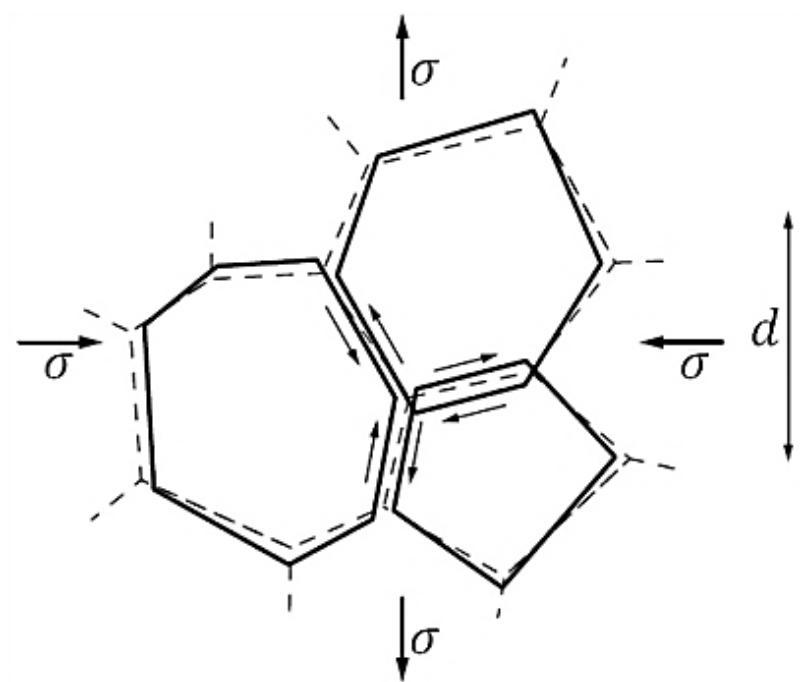

Fig. 9. Grain boundary sliding ensures the compatibility of grains which would be violated if only diffusion creep would occur [15].
The creep mechanisms discussed above differ in their temperature dependence because the activation energy of the mechanisms is different. Each of the above mechanisms leads to a different value of the stress exponent $n$ in Equation 5. The creep exponent takes values between 1 in diffusion creep and 3 in dislocation creep, with even higher values occurring in reality. Thus, depending on the external conditions, different creep mechanisms dominate the behaviour.

As already noted, depending on the temperature and the stress, different microscopic processes are important in determining creep behaviour. Creep data of this nature are represented graphically for some well-studied systems in the form of stress-temperature diagrams, which are the so-called deformation mechanism maps. These maps indicate stresstemperature regimes (or areas) over which various mechanisms operate. The great importance of mechanism maps is that it allows a person to read off the dominant mechanism under different conditions. Constant strain rate contours are often also included. Thus, for some creep situation, given the appropriate deformation mechanism map and any two of the three parameters - temperature, stress level, and creep strain rate, the third parameter may be determined (see equation 5).

Fig. 10 shows a schematic deformation mechanism map. In the diagram, the temperature and the external stress, normalised by the relevant material parameters (melting temperature and shear modulus), are used as axes so that the dominant deformation mechanism can be read off.

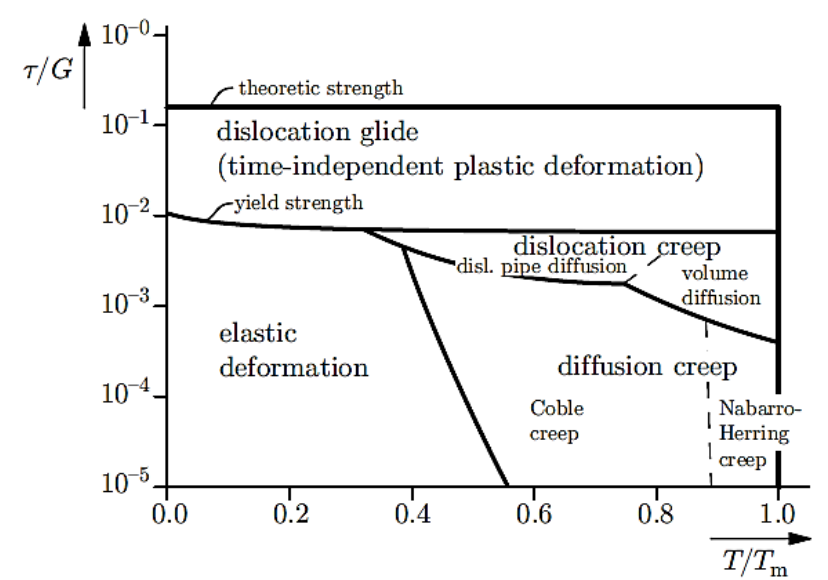

Fig. 10. Idealised deformation mechanism map [15][17].

From Fig. 10, at low external stresses and low temperatures, the material deforms elastically. At higher temperatures, diffusion creep starts, being stronger at small stresses than dislocation creep because of its lower creep exponent. Because of the lower activation energy for grain boundary diffusion, this mechanism is more important than bulk diffusion at low temperatures. Since the creep exponent is the same in both cases, the two regions are separated by a vertical line.

At larger stresses, dislocation creep with its larger creep exponent becomes dominant. Vacancy diffusion along dislocation lines is more important than diffusion through the bulk material at lower temperatures since its activation energy is smaller. Because the creep exponent is larger for diffusion along the dislocations than through the bulk, the separating line is inclined. 
At even higher stresses, time-independent plastic deformation begins. The theoretical strength of the material is reached at about one tenth of the shear modulus. Diagrams like this are sometimes compiled for different materials and material states. In other words, deformation maps vary for different materials

Since creep processes are time-dependent, the dominant mechanism is found to depend on the strain rate, $\dot{\varepsilon}$. The idealized dependency on $\dot{\varepsilon}$ is shown in Fig. 11 .

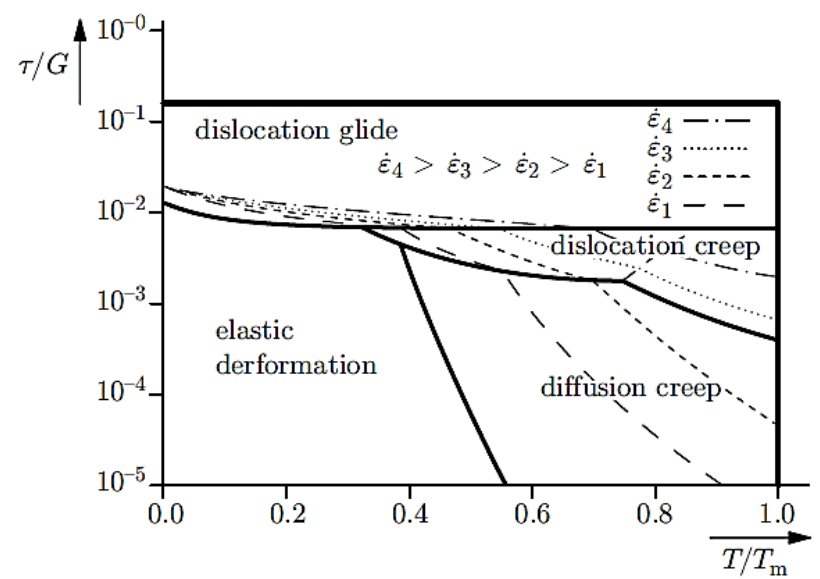

Fig. 11. Idealised deformation mechanism map at different strain rates [15].

At high strain rates i.e., high stresses, diffusion creep becomes less important in comparison to dislocation creep.

\section{Strengthening Mechanisms Against Creep}

Creation of many grain boundaries to strengthen a steel, as is the case in low temperature application, a process referred to as Grain boundary strengthening is not suitable in creep applications.

The grain size affects the creep properties, particularly so in diffusion creep. It has been shown that creep rate is inversely proportional to the square of the grain size, and so creep is favoured if the grains are small. In other words, increase in grain diameter reduces creep rate since matter has to diffuse further to cause elongation. It has been long established that smaller grains permit more grain-boundary sliding, which results in higher creep rates. The coarser (or larger) the grain is, the longer the diffusion paths of the vacancies thus reducing the strain rate. In other words, the larger the grain size, the better is a material's resistance to creep. Hence, large grains are advantageous in materials that creep.

An example of where increasing grain size has been used to reduce diffusion creep is in the manufacture of single crystal blades of gas turbines. Grains elongated in the load direction are also found to be advantageous because, due to their larger area, they reduce the shear stresses that evolve along grain boundaries during diffusion creep. Elongated grains can be achieved, for example, by drawing wires.

Work hardening is not used in creep design since a large initial dislocation density would rapidly reduce by recovery processes to a value that is determined by temperature and strain rate, destroying any initial hardening effect.

Mechanisms that impede dislocation movement are normally employed in producing creep-resistant materials.
However, these mechanisms have to be temperature resistant. The mechanisms of interest as far as creep design is concerned are:

1. Solid-solution hardening, provided the dissolved elements have a large activation energy for diffusion and are thus diffusing slowly

2. Precipitation hardening, provided the precipitates are coherent and finely distributed in the matrix and

3. Dispersion-strengthening, provided the dispersoids are small and uniformly distributed. In the matrix.

In solid-solution hardening, the high-melting foreign atoms introduced into the matrix contribute significantly to the creep strength because their bonds with the matrix atoms are usually strong, causing a limited mobility and thus making it difficult for dislocations to take the atoms with them. In precipitation hardening, dislocations are constrained to move in the small channels between the cuboid precipitates, forming highly elongated dislocation loops [19]. This impedes dislocation movement and causes the high strength of the alloy. The dislocations can cut the particles only at rather high stresses.

Precipitation affects the solute left in solution in the ferrite thereby affecting the strength contribution by solidsolution strengthening. This depletion is believed to be an important consideration of the long-term creep life. Modelling method which shall be discussed in future review had attempted to factorize quantitatively the contribution made by each of the precipitate phases, and by solution strengthening due to each solute, to the long term creep strength [22].

Dispersion-strengthening mechanism involves dispersing small particles in a material matrix [19]. Dispersionstrengthened materials have been reported to have a high creep resistance. This unusual creep property is caused by the interaction of the dislocations with the dispersoids. However, the dispersoids are small enough to be easily passed by climbing. Nevertheless, they strongly impede dislocation movement because the line tension of the dislocation is reduced at the interface to the dispersoid, resulting in an attractive interaction. To detach the dislocation from the dispersoid, a high stress is required. If the external stress is not sufficient, part of the required energy has to be provided by thermal activation. Because the required energy depends on the external stress, which thus enters the Boltzmann factor in the exponent, the dependence on the stress is unusually strong and can be approximately described by a power law with large creep exponent.

Impurity-induced embrittlement is a severe problem in the power generation industries, both at the fabrication stage and during prolonged service at elevated temperatures [2]. A solute causes embrittlement by reducing the cohesion across the boundary plane. On the other hand, those solutes which enhance covalent bonding normal to the boundary must reduce embrittlement. This undesirable phenomenon deteriorates toughness during prolonged service at elevated temperatures. Therefore this phenomenon is usually factored in when designing creep steels for long time application. Hence, it is one of the many challenges in successful design of long-lasting creep steels.

\section{Parametric Models}


Equation (5) can be integrated to find the creep rupture time $t_{r}$ as

$\ln \left\{t_{r}\right\}=\ln \left(\frac{\varepsilon_{r}}{K_{3}}\right)-n \ln \{\sigma\}+\frac{Q_{c}}{\bar{R} T}$

Equation 7 is what is known as a physical relationship. Nevertheless, it is found in practice that slightly better fits are obtained by writing [16][23][24]:

$\ln \varepsilon_{r}=k_{4}+k_{5} \sigma+k_{6} T$

where $k_{4}, k_{5}$, and $k_{6}$ are fitting constants. Equation 8 is what is known as an empirical relationship.

In steel design for power plants these relationships for creep rupture time must be able to extrapolate to much longer times and service conditions. It is reported that between the above physical and empirical relationships, it has yet to be demonstrated which extrapolates better.

Alternatively, from equation 5, the flow stress corresponding to a given creep rate may be written as [25]:

$\sigma=\left(\frac{\dot{\varepsilon}_{S S}}{K_{3}}\right)^{1 / n} \exp \left(\frac{Q_{c}}{n \kappa T}\right)$

The values of $K_{3}, n$, and $Q_{c}$ vary with material and have to be found experimentally. The values of $n$ and $Q_{c}$ also vary in different stress-temperature regimes, this is due to different mechanisms determining the creep behavior. The values of $n$ and $Q_{c}$ also depend on the material microstructure. For example, it has been shown [14] that $n$ and $Q_{c}$ are much higher for particle-hardened alloy compared to the matrix of ferrite at stresses higher than $\approx 30 M p a$. Evans and Wilshire (1993) obtained for ferrite matrix material $n \approx 5, Q_{c} \approx 260\left(\mathrm{kJmol}^{-1}\right)$ and $n \approx$ $12, Q_{c} \approx 600\left(\mathrm{kJmol}^{-1}\right)$ for precipitation-hardened alloy $\left(\frac{1}{2} \operatorname{Cr} \frac{1}{2} M o \frac{1}{4} V\right)$.

Dimitriu and Bhadeshia (2007) in their study tried to relate creep rupture and hot tensile strength using equation 6.3. Assuming that the creep failure time $t_{f}$ is related to the creep rate via $n\left(\dot{\varepsilon}_{S S}\right) t_{f} \cong 1$, it follows from their analysis that the failure stress $\sigma_{f}$ is given by [25]:

$\sigma_{f} \cong\left(\frac{1}{K_{3} n t_{f}}\right)^{1 / n} \exp \left(\frac{Q_{c}}{n \kappa T}\right)$

If it is assumed that Equation 10 can now be used to indicate a hot tensile test by setting $t_{f}$ to a sufficiently small value, then the activation energy for a hot tensile test becomes equivalent to that for creep. This analysis using creep models assumes that the mechanism operating in the hot tensile test is identical to that in a creep test for temperature greater than $T_{\mathrm{T}}$ where $T_{\mathrm{T}}=510-570^{\circ} \mathrm{C}$. However, the equation has not been used to justify the relationship between a hot tensile test and a creep test. But their exist overwhelming observation from a neural network model [25] that there is a clear existence of a relationship between creep rupture data and hot tensile strength for $T>T_{\mathrm{T}}$. This implies that hot strength tests could in research programmes be used as rough indicators of the temperature sensitivity of creep rupture data. This may not be too farfetched if for $T>T_{\mathrm{T}}$, the mechanism remains thermally activated dislocation motion for both tensile and creep deformation.
There are other fundamental theories describing the process of creep deformation and rupture life in different regimes of stress, temperature and strain rate, but the theories have not been applied successfully in the design of real materials for engineering application. This is because practical materials tend to be complex.

In general, the steady-state creep strain rate for metals is a function of the applied stress $(\sigma)$, the absolute temperature $(T)$, and the grain size $(d)$ and can be represented thus [26]:

$\dot{\varepsilon}=f\{\sigma, T, d\}$

This can be written explicitly as

$\dot{\varepsilon}_{S S}=\alpha_{1}\left(\frac{D G b}{\kappa T}\right)\left(\frac{b}{d}\right)^{m}\left(\frac{\sigma}{G}\right)^{n}$

where $\dot{\epsilon}_{S S}$ is the steady-state creep rate, $\alpha_{1}$ is usually an empirical constant, $D$ is an appropriate diffusion coefficient usually given as

$D=D_{0} \exp \left(-\frac{Q}{R T}\right)$

$D_{0}$ is pre-exponential term in diffusion coefficient, $Q$ is the activation energy, $R$ is the real gas law constant (universal gas constant). $G$ is the shear modulus, and $b$ is the magnitude of the Burgers vector. The stress-exponent $n$ and the grain size exponent $m$ are dependent on the mechanism of creep. The Equation 11 above is known as the constitutive creep equation.

For particle hardened metals, an effective stress $\left(\sigma-\sigma_{o}\right)$ is used where $\sigma_{o}$ is a threshold or friction stress so that Equation 11 becomes

$\dot{\varepsilon}_{S S}=\alpha_{1}\left(\frac{D G b}{\kappa T}\right)\left(\frac{b}{d}\right)^{m}\left(\frac{\sigma-\sigma_{0}}{G}\right)^{n}$

Failure to apply this is reported to result in artificially large stress-exponents.

Equation 11 can be expressed thus for creep strain:

$\dot{\varepsilon}=\alpha_{1}\left(\frac{D G b}{\kappa T}\right)\left(\frac{b}{d}\right)^{m}\left(\frac{\sigma}{G}\right)^{n} t$

where $t$ is creep time. Taking logarithm of this constitutive creep equation will yield

$\ln \varepsilon=n \ln \left(\frac{\sigma}{G}\right)+\ln \left(\frac{G b}{\kappa}\right)+\ln D_{0}-\frac{Q}{R T}-\ln T+m \ln \left(\frac{b}{d}\right)+$ $\ln t$

This form of equation has been used in predictive neural network modelling. In such a case, the input variables were taken as $1 / T, \ln (T), \ln \left(\frac{\sigma}{G}\right)$, and $\ln (t)$. They are the four important variables on which the creep strain $\ln (\varepsilon)$ depends. This is done to improve the prediction of the creep strain by the model.

Creep strain is a direct measure of remaining life so the safe extrapolation of short-term creep data is a major goal of structural integrity assessment. There exist a large number of empirical or semi-empirical methods, which permit the accurate representation of experimental data and at the same time facilitate the extrapolation of short-term creep data, to varying degrees of success [27].

A popular empirical method involves the use of a $\theta$-parameter equation [28]. In this method, creep data 
from short term experiments and hence of small strains, are evaluated and extrapolated to larger strains $\varepsilon$ using the equation due to Evans and Wilshire [15]:

$$
\varepsilon=\underbrace{\theta_{1}\left[1-\exp \left(-\theta_{2} t\right)\right]}_{\text {decaying rate }}+\underbrace{\theta_{3}\left[\exp \left(\theta_{4} t\right)-1\right]}_{\text {accelerating rate }}
$$

where $\theta_{i}$ are obtained by fitting to experimental data, and $t$ is the time at temperature. The first two of these parameters describe the primary or decaying strain rate component, whereas the remaining terms the accelerating regime.

Maruyama, et al. (1990) in their prediction of long term creep rupture life of $2.25 \mathrm{Cr}-1 \mathrm{Mo}$, used constitutive creep equation of steady-state stage of the form:

$\varepsilon=\varepsilon_{0}+A[1-\exp (-\alpha t)]+B[\exp (\alpha t)-1]$

where $\varepsilon_{0}, A, B, \alpha$ are parameters determined by curve fitting to a measured creep curve. It is almost the same as the $\theta$-parameter method discussed previously. This equation is reported to be able to represent creep curves up to the tertiary creep stage. The parameters are formulated as simple functions of stress and temperature, and they can be extrapolated to long-term creep properties with a lower stress and a lower temperature [29].

Maruyama et al. (1990) summarized that rupture life was linearly related to the following rupture parameter $P$ derived from the creep equation [30][31]:

$P=\left(\frac{1}{\alpha}\right) \ln \left\{\frac{\varepsilon_{T}-\varepsilon_{0}-A}{B}\right\}$
While parametric models described above have been widely and successfully applied, they simply are not sufficiently general to deal with large numbers of variables as is the case in creep steel design. A more modern technique is the neural network method (in Bayesian framework), which thrives in complexity. The method has now been demonstrated to be superior in the extrapolation and representation of creep data. This method is now strongly advocated as a better way of treating creep data with the aim of developing product and design standards.

\section{Conclusion}

The physical metallurgy theories and parametric models that have been the bases in the design of steel for fossil thermal plant applications have been reviewed. No doubt, the models developed have recorded significant success in accurate representation of short-term experimental creep data and extrapolation to higher temperatures. Unfortunately, they appear not to be sophisticated enough to deal with large numbers of variables involved in reliable design of creep steel for power plant, for example, accounting for precipitation that takes place throughout the life of the creep steel in service. To deal with this issue, phase stability models and neural network analysis has been put forward as the better alternative in creep steel design. This modelling method and its application will be the subject of future review.

References

1. Thomson, R. C. (1992): Carbide Composition Changes In Power Plant Steels As A Method Of Remanent Creep Life Prediction, $\mathrm{PhD}$ Thesis, Department of Materials Science and Metallurgy, Newnham College, University of Cambridge

2. Bhadeshia, H. K. D. H. (2001): Design of Ferritic Creep-resistant Steels, ISIJ International, Vol. 41, No. 6, pp. 626-640.

3. Cole, D. G. (2000): Designs of Heat-Resistant Steels for Small Power Plant, PhD Thesis, Materials Science and Metallurgy, Darwin College, University of Cambridge.

4. Bhadeshia, H. K. D. H. (2007): Novel Aspects of Ferritic Steels for the Generation of Electricity, 4th International Symposium on Mechanical Science based on Nanotechnology, Sendai, Japan, p. 143-146.

5. Bhadeshia, H. K. D. H. (1999): Estimation of the Microstructure and properties of Ferritic Creep-Resistant Steels, in Modelling Of Microstructural Evolution In Creep Resistant Materials, eds. Strang, A. and McLean, M., The Institute of Materials, London, pp. 15-38.

6. Bhadeshia, H. K. D. H. (1999): Design of Creep-Resistant Steel Welds, in Trends in Welding Research, eds. S. A. David, T. DebRoy, J. A. Johnson, H. B. Smartt and J. M. Vitek, ASM International, Ohio, pp. 795-804.

7. Bhadeshia, H. K. D. H. (2013): Creep-Resistant Steel-Case Study, in Kinetics and Microstructure Modelling Lecture note for Course MP6, Department of Materials \& Metallurgy University of Cambridge, pp. 1-6.

8. Takeda, Y. \& Masuyama, F. (1991): Heat-Resisting Steels for Ultra Super Critical Fossil Power Plant, Heat-Resistant Materials, ASM Int., 1st International Conference on Heat Resisting Materials, Wisconsin, USA.

9. Abe, F. (1999): High Performance Creep Resistant Steels For 21st Century Power Plants, National Institute for Materials Science (NIM), Japan.

10. Muramatsu, K (1999): Advanced Heat Resistant Steel for Power Generation, The University Press, Cambridge, UK, p. 543.

11. Tancret, F., et al., (2003): Design of a Creep Resistant Nickel Base Superalloy for Power Plant Applications Part 1 - Mechanical properties modelling, Materials Science and Technology, Vol. 19, pp. 283-290.

12. Callister, W. D. (2007): Materials Science And Engineering: An Introduction, 7th ed., John Wiley \& Sons, Inc. New York, pp. 238243.

13. Cole, D., et al. (2000): Modelling Creep Rupture strength of Ferritic Steel Welds, Science Technology of Welding of Joining, Vol. 5, No. 2, p. 81-88.

14. Askeland, D. R., and Fulay, P. P. (2010): Essentials of Materials Science and Engineering, 2nd ed., Cengage Learning, Stamford, PP. 217-219.

15. Rösler J., et al. (2007): Mechanical Behaviour of Engineering Materials: Metals, Ceramics, Polymers, and Composites, SpringerVerlag Berlin Heidelberg, pp. 383-401.

16. Bhadeshia, H.K.D.H., et al. (1998): Ferritic Power Plant Steels: Remanent Life Assessment and Approach to Equilibrium, International Materials Reviews, Vol. 43, No. 2, pp. 45-69.

17. Ashby, M. F. and Jones D. R. H. (1989): Engineering Materials 2: An introduction to microstructures, processing and design, Materials science and technology, Elsevier science, Oxford, Vol. 39.

18. Weertman, J. (1995): Theory of Steady-State Creep Based On Dislocation Climb, Journal of Applied Physics, Vol. 26, pp. 12131217.

19. Smallman, R. E. and Ngan, A. H.W. (2007): Physical Metallurgy and Advanced Materials, 7th ed., Elsevier Ltd, Oxford, pp. 394.

20. Porter, D. A. and K.E. Easterling, K. E. (1992): Phase Transformations in Metals and Alloys, 2nd ed., Chapman and Hall, London, pp. 60-105.

21. Bocquet, J. L., et al. (1996): Diffusion in Metals and Alloys, in Physical Metallurgy, 4th ed., Cahn, R. W., and Haasen, P. (eds.), Elsevier Science, Amsterdam, Netherlands, pp. 535-651.

22. Murugananth, M. and Bhadeshia, H.K.D.H (2002): Mathematical Modelling of Weld Phenomena - VI, Cerjak, H. and Bhadeshia, H.K.D.H, eds., Institute of Materials, pp. 243-260.

23. Cane, B. J. (1981): Interrelationship Between Creep Deformation and Creep Rupture in 2.25Cr-1Mo steel, Metal Science, Vol. 13, pp. 287-294. 
24. Evans, R. W. and Wilshire, B. (1993): Introduction to Creep, The Institute of Materials, London, pp. 1-75.

25. Dimitriu, R. C. and Bhadeshia, H. K. D. H. (2007): Hot Strength Of Creep Resistant Ferritic Steels and Relationship to Creep Rupture Data, Materials Science and Technology, Vol. 23, pp. 1127-1131.

26. Bhadeshia, H. K. D. H. and Sourmail, T. (2003): Design of CreepResistant Steels: Success and Failure of Models, Japan Society for the Promotion of Science, Committee on Heat-Resisting Materials and Alloys, Vol. 44, pp. 299-314.

27. Bhadeshia, H. K. D. H. (1999): Neural Networks in Materials Science, ISIJ International, Vol. 39, pp. 966-979.

28. Evans, R. W. and Wilshire, B. (1985): Creep of Metals and Alloys, The Institute of Metals, London, pp. 1-104.

29. Maruyama, K., et al. (1990): Prediction of Long Term Creep Curve and Rupture Life of 2.25Cr-1Mo Steel, ISIJ International, Vol. 30, pp. 817-822.

30. Maruyama, K. and Oikawa, H. (1987): An Extrapolation Procedure Of Creep Data for St Determination With Special Reference To CrMo-V Steel, Trans ASME, J. Pressure Vessel Technology, Vol. 109, pp. 142-146.

31. Maruyama, K., et al. (1986): Formulation of Creep Curves and Rupture Lives for Long-Term Creep Property Prediction With Special Reference to a $12 \mathrm{Cr}(\mathrm{H} 46)$ Steel, Transactions of the Iron and Steel Institute of Japan, Vol. 26, pp. 212. 